\title{
A GEO-REFERENCED DATABASE TO MANAGE THE LANDSCAPE AREAS UNDER PRESERVATION IN LOMBARDY REGION
}

\author{
A. Cazzani ${ }^{1} *$, M.Aresi ${ }^{2}$, S.Coloru $^{3}$, D.Giannoccaro ${ }^{1}$ \\ ${ }^{1}$ DASTU - Dipartimento di Architettura e Studi Urbani (Department of Architecture and Urban Studies), \\ Politecnico di Milano, Italy - alberta.cazzani@ polimi.it \\ ${ }^{2} \mathrm{PhD}$ architect and DASTU - Dipartimento di Architettura e Studi Urbani \\ (Department of Architecture and Urban Studies), Politecnico di Milano, Italy, - monica.aresi@gmail.com \\ ${ }^{3}$ Architect and DASTU - Dipartimento di Architettura e Studi Urbani \\ (Department of Architecture and Urban Studies), Politecnico di Milano, Italy, - stefano.coloru@alice.it \\ ${ }^{1}$ DASTU - Dipartimento di Architettura e Studi Urbani (Department of Architecture and Urban Studies), \\ Politecnico di Milano, Italy - daniela.giannoccaro@polimi.it
}

KEY WORDS: Landscape preservation, Regione Lombardia Landscape Plan (PPR), openGIS.

\begin{abstract}
:
One of the main goals of the Lombardy Region Landscape Plan (Piano Paesaggistico Regionale - PPR) review was to set up a detailed investigation of landscape binding actions that are issued according to article 136 of the Code of Cultural Heritage and Landscape (D.Lgs. 42/2004).

To achieve this goal, a survey was launched and a geo-referenced database was constructed, considering all the data included in the 888 landscape binding actions currently in force in Lombardy.

The geo-referenced database takes into account also other architectural preservation measures and natural landscape protections, because a large quantity areas in Lombardy are safeguarded as Regional Parks and Natural Monuments, ecological corridors, geosites and various zones with natural significance are issued as ZPS and SIC by UE.

Databases from other agencies and institutions were collected, examined and updated, to provide a complete tool, usable by public administrations and professionals.

Such database can also be integrated by multi-temporal geoinformation availability of applications implemented to manage and share georeferenced historical maps (i.e. GEOPAN ATL@S APP), boosting the utility of these data sets in the daily professional activity ${ }^{1}$.

\section{INTRODUCTION}

The Lombardy Region Landscape Plan, issued in 2010, is now updating in order to improve its efficiency to better manage all the types of significant Lombardy landscapes, as periurban and agricultural, and to join planning and preservation policies, like the Landscape European Convention requests.

The review of the Regional Landscape Plan (PPR) now in progress - with a scientific agreement between the Lombardy Region and the Architectural and Urban Studies Department (DAStU) of the Politecnico of Milan - must also respond to the Italian Preservation law (Code of Cultural Heritage and Landscape, D.Lgs. 42/2004) that prescribes the definition of management criteria for every landscape area under binding action.

The goal of these management criteria is to consider the complex system of Lombardy preservation in order to update the safeguard reason and to connect different protection levels. It is important to remember that the landscape preservation Italian laws were founded originally on binding actions to

natural beauty" as prescribed in the historic laws 778/1922 and $1497 / 1939$.

The idea of protection by law required the creation of a list of what is to be protected and later the definition of a custodianship and a control. Generally, natural beauties, aesthetic views, historic park and gardens eligible for listing had to be considered exceptionally important, with a lot of scenic, perceptive, geological and environmental value. In that way many natural areas were recognized and protected, but not all the landscapes with national importance.

In Lombardy Region particularly lakeshores, river shores, mountain zones with spectacular views to the Alps and several hundred historic gardens are declared under National protection: it is a complex heritage that needs to be examined in order to define the requested preservation and management criteria.

This aim involves the coordinated analysis and evaluation of binding actions and preservation tools, to replace the current passive protection and to establish a new active discipline of the PPR, defining extensive preservation management criteria.
\end{abstract} protect areas "with a lot of scenic values" or "of exceptional

\footnotetext{
* Corresponding author

${ }^{1}$ The present work was conceived and written jointly by the three authors. In particular, Alberta Cazzani developed sections 2 and 3, Stefano Coloru developed section 4, Monica Aresi developed section 5, and Daniela Giannoccaro developed section 6. The authors collaborated in the writing of the Abstract, Introduction and Conclusions, and for the final revision of the manuscript.
} 


\section{LANDSCAPE PRESERVATION IN LOMBARDY}

The landscape preservation Italian laws were founded originally on binding actions to protect areas of "exceptional natural beauties", as issued in the laws 778/1922 and 1497/1939. The idea of protection by law required the creation of an inventory, a list of what is to be protected and later the definition of a custodianship and a control. Generally, natural beauties, aesthetic views, historic park and gardens eligible for listing had to be considered exceptionally important, with a lot of scenic, perceptive, geological and environmental value. In that way many natural areas were recognized and protected, but not all the landscapes with national importance were declared under National protection.

During the 50's the landscape preservation was focused on protecting areas "with a lot of scenic values" or "of exceptional natural beauty"; with particular regards in Lombardy Region to lakeshores, historic gardens, mountain zones with spectacular views to the Alps.

In 1977 the Italian Government issued the Regions, local authorities also focused on cultural heritage and landscape protection. In that way the preservation of landscape heritage is controlled by a preservation statal agency (the Soprintendenza), but is operatively delegated to the Regions that could issue other protected areas, like Regional Parks and Natural Reserves and define policies focused on landscape safeguard and promotion.

In 1985 the law 431/1985 (Legge Galasso) established Regional Plans to manage the landscape like natural and cultural resources whole, defining the need to preserve by planning instead by binding actions to conserve and manage the complexity of our heritage. That law had the goal to safeguard lakeshores, river shores, and mountains in order to control the intense transformation and urbanization and to protect natural and cultural landscapes. This law is now part of Italian Preservation Law (DL 42/2004, Codice dei Beni Culturali e del Paesaggio), particularly art. 142, Areas protected by Law: "Until the landscape plan is approved under art.156, the following are in any case subject to the provisions of this Title by virtue of their landscape interest: $a$ ) sea coastal territories including a swath of land to a depth of 300 meters from the waterline, and also land elevated over the sea; $b$ ) lake shores, territories conterminous with lakes, including a swath of land to a depth of 300 meters from the waterline and also land elevated over the lakes; $c$ ) the rivers, streams and water course indicated in the lists provided for in the lists provided for in the consolidated law on provisions for waters and electric power plants, approved by Royal Decree n.1777 on December 11, 1933, and the relative banks or base foundations of embankments for a swath of 150 meters each; $d$ ) mountains for the part exceeding 1600 meters above sea level regarding the Alps and 1200 meters above sea level regarding the Apennines and the islands; e) glaciers and glacial cirques; $f$ ) parks and national or regional reserves as well as the external protection areas of the parks; $g$ ) territories covered with forests or woods, even if marked and damaged by fire, and areas subject to reforestation...; $h)$ areas assigned to agricultural universities and zones designated for civic uses; $i$ ) marshlands included in the list provided for by Decree n.448 of the Republic President on March 13, 1976; $l$ ) volcanoes; $m$ ) zones of archaeological interest identified at the time this Code comes into force...."

Currently $24 \%$ of Lombardy Region is protected by National Park (Parco Nazionale dello Stelvio) and Regional Parks that Lombardy Region had issued from 1983 (according to the Regional Law 86/1983) to establish a system of protected areas particularly along the main rivers, around the most important lakes, considering Alpine areas and Pre-Alps Hills context, but also periurban and agricultural landscapes around Milan.

It is important to remember that Lombardy is the first agricultural Region in Italy, still intense cultivated with excellent production and with many agricultural landscapes with historic, cultural significance (like terraced vineyards, olive and citrus groves, rice fields, well designed cultivations). Of course Lombardy has also a lot of anthropization pressure with the metropolitan area of Milan and almost 10 millions of inhabitants. Landscape preservation in Lombardy has to consider this connection between extraordinary and ordinary landscapes, industrial/commercial impacts and urban development.

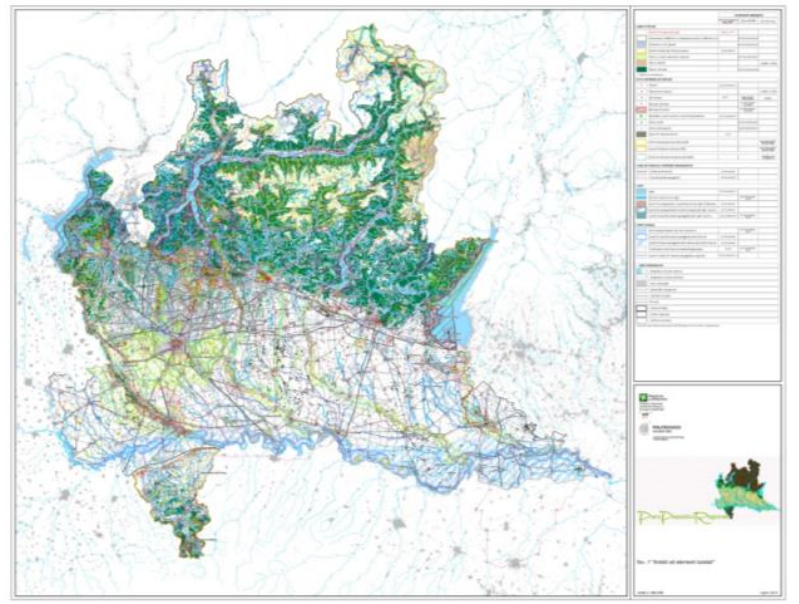

Figure 1. Lombardy Region Landscape Plan (PPR), review: landscape preservation system. $52 \%$ of Lombardy Region is under landscape protection at international, national or regional level.

Presently $52 \%$ of Lombardy Region (Figure 1) is under landscape protection at international, national or regional level: often the same area is preserved by all 3 levels. Unfortunately the fact that most of the Region is preserved does not mean that Lombardy landscape is well conserved and managed.

Till now areas under National landscape preservation needed to obtain a specific authorization in order to be transformed and or to design a new intervention. In that way the preservation is passive: it is not giving standards to protect or valorize the areas with values, but only authorizing or rejecting specific intervention requests. Unfortunately a lot of these interventions - even if they obtained a landscape authorization - have caused an extensive alterations of the Lombardy landscape and the current situation is the result of many transformations often not connected and compatible with the context. In other cases the protected areas still conserve landscape values, but the zones around them are intensely built and altered.

Indeed, referring to the European Landscape Convention (2000), it is necessary not only to protect, but also to valorize, rehabilitate and design ordinary and extraordinary landscapes. The European Landscape Convention introduced a Europe-wide concept centering on the quality of landscape protection, management and planning and covering the entire territory, not just outstanding landscapes. Considering the current Italian Preservation Law (D.Lgs. 42/2004, Codice dei Beni Culturali e del Paesaggio), it is mandatory to define management criteria for every landscape area under binding action according to art. 136 of D.Lgs 42/2004, Buildings and Areas of Notable Public Interest: "The following are subjects to the provisions of this Title by virtue of their notable public interest: $a$ ) immovable properties of outstanding natural beauty or geological 
singularity; $b$ ) the villas, gardens and parks not protected by the provisions of the Second Part of this Code, which stand out for their uncommon beauty; c) complexes of immovable things which constitute a characteristic aspect having aesthetic and traditional value; $d$ ) beautiful views considered to be of picturesque quality as well as vantage points and belvederes which are accessible to the public and from which the spectacle of those beauties may be enjoyed".

The main goal of the Lombardy Region Landscape Plan review - started in 2013, still ongoing - is to consider all the protected areas in order to preserve in a better way landscape unit with similar values, problems, potentialities. These units can be part of a bigger landscape zone (like a lakeshore, a river shore, an Alpine area) and need to be preserved and managed as a landscape system, considering the historical reasons that implicated binding actions, but also the current situation and the present landscape complexity. Referring to the current Italian Preservation Law (D.Lgs. 42/2004, Codice dei Beni Culturali e del Paesaggio), art.143 - Landscape Plan "The Landscape Plan shall contain descriptive and prescriptive content and include recommendations and proposals. Its development shall include the following phases: a) a survey of the entire land area, through the analysis of its historical, natural and aesthetic characteristics and their inter-relationship, and the consequent definition of the landscape values to be protected, reclaimed, upgraded and enhanced; $b$ ) analysis of the dynamics of land transformation through the identification of risk factors and elements of landscape vulnerability, comparison with other land programming and planning and protection actions; $c$ ) identification of landscape area and the relative aims of landscape quality; d) definition of general and operative prescriptions for protection and use of the land included in the defined areas; $e$ ) definition of measures for the conservation of the distinctive features of areas protected by law and, where necessary, definition of management criteria and work for landscape enhancement to be carried out on buildings and area declared to be of notable public interest; $f$ ) identification of work to be carried out for the reclamation and upgrading of areas that have been significantly compromised or degraded; $g$ ) identification of the measures necessary to ensure that work changing the aspect of the territory be harmonized with the landscape context, with actions and investments for the sustainable development of the areas concerned being under the obligation to refer to the aforesaid measures; $h$ ) identification, under article 134, letter c), of any categories of buildings or areas, different to those indicated in articles 136 and 142, to be subjected to specific safeguarding and use measures".

\section{ANALYSIS OF THE SITES AND AREAS UNDER NATIONAL LANDSCAPE PRESERVATION IN LOMBARDY}

The review of the Regional Landscape Plan (PPR) now in progress - in order to respond to the Italian Preservation law (Code of Cultural Heritage and Landscape, D.Lgs. 42/2004) set up as one of its main goals a detailed analysis of the 888 landscape binding actions that are issued according to the D.Lgs. 42/2004, article 136 and a geo-referenced database was constructed.

A variety of data was examined, like administrative, landscape characters and values, borders, connections with other architectural, landscape, natural protections.

All this made possible to better understand the articulation and integration of the Lombardy landscape preservation and, more specifically, to define coordinated management criteria. Last but not least, databases from different institutions were compared, rearranged and updated to provide a geo-referenced data base that is as complete and clear as possible, usable by administrations and professionals.

The goal was to build a geo-referenced data base in order to define coordinated preservation criteria, updatable and usable within open source GIS (but also within commercial GIS licenses (as ESRI $\odot$, or to deploy new WEBGIS or APP).

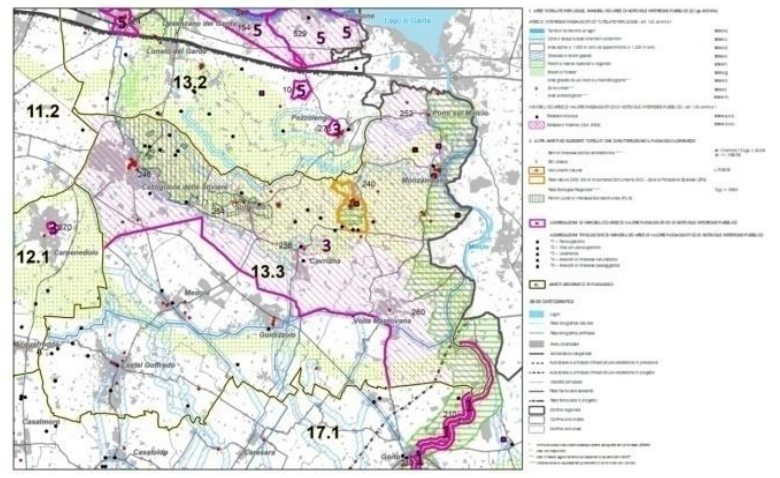

Figure 2. Lombardy PPR, review: detail of landscape preservation system around Garda Lake. It is possible to recognize the complexity of protected areas and sites that - by current preservation law - need management criteria.

In particular, the activity consisted of:

- Critical analysis of the landscape binding actions (Ministerial Decrees or Regional Council Resolutions) of the areas and sites under landscape protection according to the D. Lgs. 42/2004, art.136 in order to highlight dating, specific landscape characters, consistency, borders, safeguard effectiveness, level of permanence;

- Construction of a geo-referenced database aimed at mapping the areas under landscape protection according to the D. Lgs. $42 / 2004$, art.136 and all the characterizing information, as PPR active tool. The work was carried out both on the 556 landscape binding actions relating to the "overall beauty" and to the 332 landscape binding actions related to the "individual beauties".

- Analysis of the relations between the 888 landscape binding actions and the areas, sites and assets under other international, regional and local protections in the Lombardy Region.

The analytical and critical reading of the characteristics and landscape specificities of the landscape preserved areas and sites in Lombardy was elaborated examining the decrees in two main databases, the SIBA (Sistema Informativo Beni e Ambiti Paesaggistici - Landscape sites and areas Information System of Lombardy Region), and the SITAP (Sistema Informativo Territoriale Ambientale e Paesaggistico - Environmental and Landscape Information System of MIBAC - Ministero per i Beni e le Attività Culturali - Ministry of Cultural Heritage and Activities).

The system of bonded areas and sites according to article 136 as already noted is quantitatively very consistent and unfortunately the reference data are not always accurate and reliable. In fact, the classification of the constrained areas carried out by the Region with the SIBA has introduced a new numbering with respect to the ministerial one (reported in SITAP web-GIS) and sometimes relative to the same area there are significant differences in the perimeter between the two systems. The reading of the specific decrees has also allowed to recognize how often - although diversified acts have been issued - the reasons for the protection are the same and are repeated for adjacent areas. In this regard, the numerous landscape binding 
actions established along the Ticino river or along the coasts of the lakes show a very similar motivation, without reference to local specificities. This consideration further strengthens the program of defining unitary criteria for homogeneous systems.

A long work consisted therefore in finding, analyzing and reorganizing all the decrees in order to highlight situations of overlaps / substitutions (areas under preservation that over time have been extended or aggregated; areas of respect of a preserved area issued by a different preservation decree that must obviously be treated in a coordinated way, etc.) in order to have a more clear and updated situation and to be able to face the problems, particularly about the bonded sites and areas boundaries. These boundaries sometimes refer to cadastral data (not always available), other times to geographical indications such as distances from the coast, roads, railways, traces of a path that may have changed over time.

A further element of research concerns the bonded architectural sites according to the Law 1089/1939 (now article 10 of D.Lgs. 42/2004): a significance presence of monumental assets is important to define integrated preservation criteria and also because for example bonded gardens and parks are often connected with villas under architectural/cultural protection and it is therefore necessary to define unitary management methods. A geo-referenced database was so compiled containing a series of information useful for identifying critical elements, values and potential of the protected landscape heritage, as well as identifying the possible combinations of areas and sites subject to landscape protection, useful for defining protection criteria and coordinated enhancement, aimed at the protection and planned preservation of preserved areas and sites, in order to adapt the Regional Landscape Plan to the requirements of the Code of Cultural Heritage and Landscape.

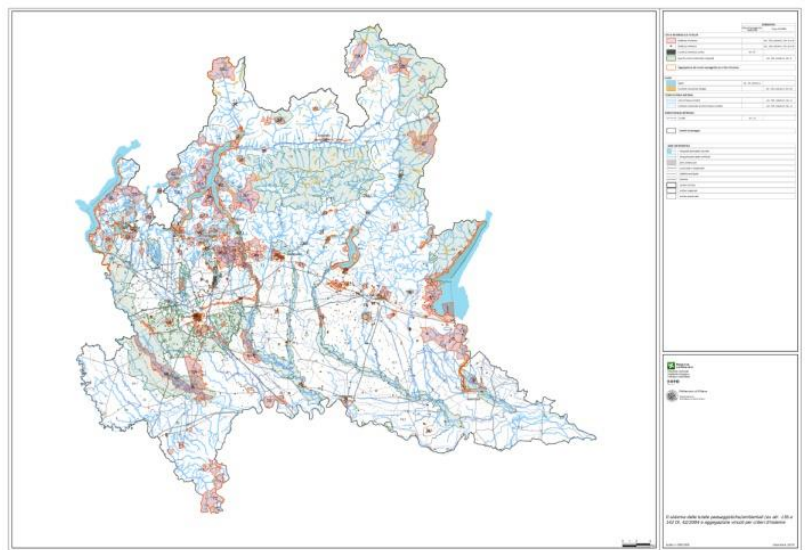

Figure 3. Lombardy PPR, review: the aggregations of bonded areas and sites (in red) in order to define landscape preservation extensive criteria involving a system of protected areas, often geographically connected and referring to Landscape settings (in black).

Lombardy landscape preservation must be joined with planning policies and practices: for this reason before preparing a single criteria for each bonded area, the Lombardy PPR review issues extensive preservation management criteria, referring to a system of protected areas, often geographically connected.

Thanks to the work of analyzing the decrees of landscape binding actions, it was possible to define aggregations of sites and areas preserved by art.136 of D.Lgs 42/2004 as considered "of landscape value and considerable public interest" to estabish criteria of protection and enhancement. In particular, in July 2017 (Figure 3):
- 60 aggregations of bonded sites and areas "of landscape value and of considerable public interest" concerning the "overall beauties", based on homogeneous or significantly connected landscape, territorial or geographical features;

- 5 typological aggregations of bonded sites and areas "of landscape value and of considerable public interest" involving the "individual beauties" based on similar typological characters (parks and gardens, villas with parks or gardens, hunting areas, sites of naturalistic interest, areas of landscape interest) were identified:

The definition of the extensive preservation management criteria is therefore consistently integrated with the PPR rules and regulations, in order to make landscape planning more connected with its protection. This initiative involves the coordinated management of binding actions and preservation tools, to replace the passive protection now being used and to establish a new normative discipline of the PPR.

On July 21, 2017 a Protocol Agreement between MIBACT (Ministero per i Beni e le Attività Culturali e il Turismo Ministry of Cultural Heritage and Activities and Tourism, now MIBAC - Ministero per i Beni e le Attività Culturali - Ministry of Cultural Heritage and Activities) and the Lombardy Region was signed. The Protocol Agreement establishes mutual commitment to develop a Regional Landscape Plan for Lombardy following the Cultural Heritage and Landscape Code. The subsequent establishment of the Joint Technical Committee between MIBAC and the Lombardy Region, which operates in agreement with the Regional Commissions for Landscape Heritage, will ensure that the new Lombardy PPR is in compliance with the Code of Cultural Heritage and Landscape, D.Lgs. 42/2004). The protocol agreement issued also the possibility to determinate specific prescriptions and management criteria for the landscape areas preserved according to art. 136 of D.Lgs. 42/2004 also for aggregates of contiguous and homogeneous sites and/or for typological groupings. Considering this Protocol the aggregations of bounded sites and areas were analyzed and approved by the Joint Technical Committee in 2018.

\section{GOALS AND MAIN CONTENTS OF THE GEO- REFERENCED DATABASE}

The already mentioned study of the 888 landscape bonded areas and sites in Lombardy considered the MIBAC Circular n.30/2011 aimed at developing a comprehensive analysis of the landscape bonded area and sites in order to define preservation management criteria.

In particular, in Lombardy there are currently 556 "overall beauties" established by D.Lgs.42/2004, article 136, paragraph 1 , letters c) and d) are the complexes of immovable property that make up a characteristic appearance having an aesthetic and traditional value, including the centers and historical centers; panoramic beauties and likewise those viewpoints or viewpoints accessible to the public, from which it is possible to enjoy the spectacle of those beauties.

"Individual beauties" are (according to the art. 136, paragraph 1, letters a) and b) of D.Lgs. 42/2004) two other categories of generally less extensive areas and sites, more limited that SIBA identifies as points, even if they are areas, specifically: immovable property that has conspicuous features of natural beauty, geological singularity or historical memory, including monumental trees; villas, gardens and parks, not protected by the Part II of Code of Cultural Heritage and Landscape, that stand out for their uncommon beauty.

The sources for the recognition and investigation of these Lombardy binding actions, were the web-GIS System SIBA and 
SITAP. These are sources that should be equivalent regarding the quantity and quality of data but, for various reasons, there are many differences, deficiencies and a lot of outdated data. The definition of the geo-referenced data base is a starting point to make order and - once the update is completed - to get a tool that will be used, as a common source among different public bodies and professionals.

The increasing of Open Data availability of historical and current information through Spatial Data Infrastructure to support landscape analysis and planning has been increasing for many years (Brumana at al., 2013), allowing to access to different geodata informative layers; in the meanwhile innovative Virtual hubs (Mazzetti, 2015) for facilitating access to open data coming from different sources (i.e. regional and national geoportal, archives, municipality territorial sites) has been adopted to facilitate the generation of advanced web applications based on the historical maps together with other data, as in the case of risk map data (Previtali et al., 2018).

The PPR layer deployed by Lombardy Region can be in the future easily brokered by such hubs in order to facilitate their discovery by the professionals and their on site desktop use within common open source GIS (as QGIS) or commercial licenses. But they could be also brokered to implement new applications for citizen purposes integrating such data with the other available data and application based on historical data sources, or best practices carried out using such data within proactive preservation design purposes.

The analysis of the landscape preservation binding actions according to art.136 of D.Lgs. 42/2004 recognized 4 large categories of landscape features cited in the motivation of interest and of uncommon beauty that led to the recognition of exceptional landscape value and therefore a duty to protect:

$\mathrm{N}$ - natural, environmental, geomorphologic characters, described in the binding action decrees as naturalistic areas, biotope, naturalistic oasis, geological singularity, natural monument, Alpine and pristine landscape;

C - cultural landscape features (anthropization work), described in the binding action decrees such as: presence of rich and valuable vegetation, parks and woods, agricultural areas of landscape value, landscape morphology (built/terraced landscape);

A - architectural, historical, urban features mentioned in the binding action decrees such as: traditional aesthetic value, historical buildings, architectures, villas with gardens, urban settlements, historic centers, fortifications and defensive works; $\mathrm{P}$ - aesthetic and perceptive values, views and vistas described such as: natural framework of uncommon beauty, panoramic beauty, Belvedere and points of view.

During the analysis of the binding action decrees it seemed appropriate also to consider whether there are landscape and/or architectural elements generically cited by the decree, without a precise description (for example: systems of villas, mountains, tree rows, lake views, green, pristine valleys, etc.), or if in the decree landscape and/or architectural elements are specifically cited with the proper name and sometimes explicated in a detailed way (as San Giovanni farm, Villa Borromeo, Naviglio canal, the glacier of the mountain Cevedale, etc.)

The analysis considered also if the binding action:

-refers to only one Municipality and it is single;

-refers to two or more municipal territories and it is multiple;

- refers to the entire territory of a Municipality/of different Municipalities and it is total;

- refers to a portion of the territory of a Municipality/ of different Municipalities and it is partial.
The problems related to the binding action borders, derive first of all from a different basic cartography on which the bounded areas and sites are represented: the Ministry webGIS system SITAP uses IGM at 1:25.000 scale and the Lombardy Region system SIBA uses CTR at 1:10.000 scale.

One of the issues that does not allow to directly compare the SITAP / SIBA data is the different referred cartography. Also in SIBA there are 556 "overall beauties" and 332 "individuals beauties" (represented by a dot), while in SITAP there are 681 polygonal and 138 point binding actions as the "individual beauties" are mapped with polygons, sometimes with points.

The critical analysis of the Lombardy binding action, comparing the Ministry and the Regional web-GIS system was necessary to better understand the landscape preservation system, considering different info and data from diverse agencies in order to create a common geo-referenced data base.

\section{THE STRUCTURE OF THE GEOREFERENCED DATABASE}

Considering the critical analysis of the binding actions a specific geo-referenced database about the landscape preserved areas and sites in Lombardy was set up.

For each of the 888 binding actions, the database contains a multiplicity of data which are:

-"personal" data of the bonded area, extrapolated directly from the decree such as SIBA code, SITAP code, law establishing the decree, dates of the decree and publication in the Official Bulletin, title and declaration, presence or absence of management criteria;

- administrative data: on which Municipality/Municipalities the binding action insists and if it regards the Municipality partially or entirely; Province; extension of the protected area in $\mathrm{Km} 2$;

- data relating to the boundaries of the bonded area: type of boundaries (synthetically identified among the following categories: administrative, geo-morphological, altitude, infrastructures, buildings, urban settlements, cadastral, undefined, other protected areas, other), description of the boundary as cited in the decree, existence of differences in perimeter between SIBA and SITAP with specifically notes indicated in the "notes" box, presence or absence of cartography attached to the binding action and, if so, which (cadastral, CTR, PGT extract, other, if readable or not.

The binding action border is an important issue as it declares what is under National landscape preservation and needs a specific preservation agency authorization in order to manage, transform, restore that area.

Often SITAP and SIBA boundaries are very different and it is a serious problem as it is necessary to know exactly the extension of the preserved area, where it is obligatory to request the landscape authorization to intervene;

- a synthetic interpretation of the historic reasons for the preservation measure, considering the landscape characters and values cited in the binding action that distinguish bonded areas or sites through the letters $\mathrm{N}, \mathrm{C}, \mathrm{A}, \mathrm{P}$ respectively for natural, environmental, geomorphological characters; constructive characters, works of anthropization; architectural, historical, urban features; characters of aesthetic, perceptive and visual/panoramic value, also adding any elements (specific or generic) mentioned in the binding action declaration;

- reference to the PPR AGP (Ambito Geografico di Paesaggio Geographical Landscape Scope) of belonging, to the aggregation of bonded areas and sites of belonging and to the relative preservation and valorization criteria;

- overlaps between protected areas and in particular if the analyzed protected area incorporates / is partially or totally 
incorporated in other areas under landscape preservation;

-link to the pdf of the decree downloaded from SIBA of the Decree published in the original Gazzetta Ufficiale (Official Bulletin).

Like already mentioned the landscape preservation system in Lombardy involves International, National and Regional levels of protection and it is absolutely necessary to understand and consider the complexity of this system in order to manage and to plan the Lombardy landscape. The work was concentrated also to identify overlaps and connections among the 888 examined binding actions with other types of naturalistic, landscape and architectural historical protection, at different levels and in particular if the bonded area under analysis partially or totally encompasses other zones under preservation. All that considered, the geo-referenced data base includes - for every binding action - info about the connection with other protected areas or site and in particular if the binding action:

- it is inside or bordered or intersects / intercepts / overlaps with a protected area according to the Code of Cultural Heritage and Landscape, D.Lgs. 42/2004, art. 142 (the historic Galasso Law), like areas adjacent to the lakes, rivers, streams and their banks, Alpine mountains above 1600 meters, glaciers, national and regional parks and reserves, areas covered by forests and woods, areas burdened by civic uses, wetlands, areas of archaeological interest (Figure 4). It is important to consider that many of the protected areas according to art. 142 of D.Lgs $42 / 2004$, do not have a delimitation neither updated nor certain and sometimes they are not even identified and do not appear easy to identify, as some of the reference data are missing or incomplete, like in the case of archaeological zones and areas burdened by civic uses.

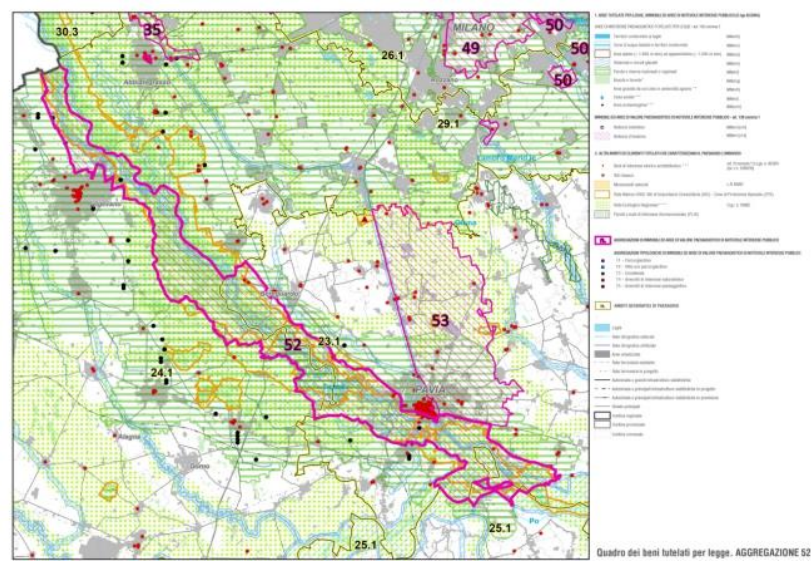

Figure 4. Aggregation 52 of bonded areas and sites regarding Ticino River Valley: landscapes preservation at National level (according to the Code of Cultural Heritage and Landscape D.Lgs. 42/2004): in pink the landscape preservation binding actions according to art.136, in green, blue and yellow

landscape preserved areas according to art 142 .

- it is within or bordered or intersects with a protected area according to Supra-National legislation, such as Natura 2000 sites, like Naturalistic ZPS zones (Zone di Protezione Speciale Special Protection Zones SPA areas), SIC sites (Siti di Interesse Comunitario - Site of Community Importance) regarding natural habitats conservation and like Unesco sites, or with other protected areas at regional level (eco-museums, natural monuments, geosites, Regional Ecological Network, Regional Green Network, PLIS) (Figure 5).

- or includes so-called monumental binding actions related to building and sites of cultural, architectural and artistic interest, according to the historic Law 1089/1939, today Code of
Cultural Heritage and Landscape, D.Lgs. 42/2004, part II, art.10, although it is not available a complete and updated database of this protected heritage.

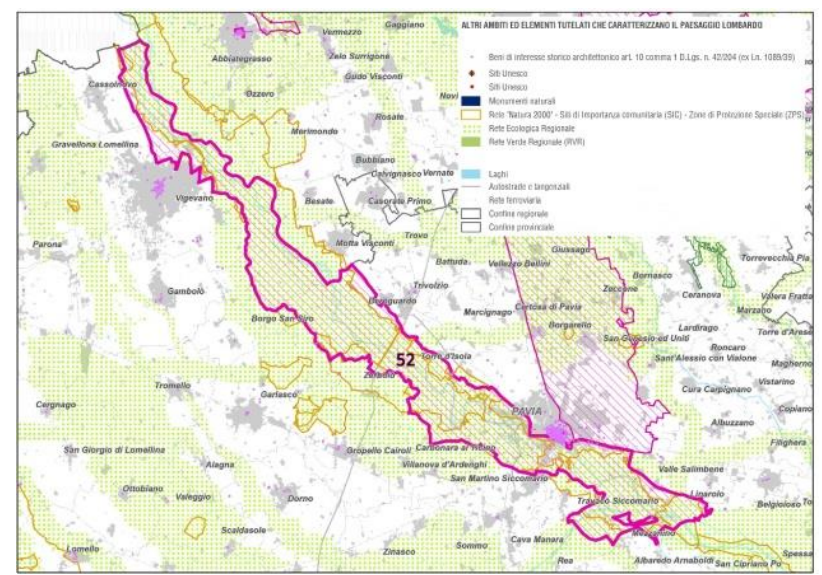

Figure 5. Aggregation 52 of bonded areas and sites regarding Ticino River Valley (in pink) and its connection with supranational protections, such as Natura 2000 sites, Unesco sites and to other protected areas at regional level (Regional Parks and Reserves, eco-museums, natural monuments, geosites, Regional Ecological Network, Regional Green Network, PLIS).

The geo-referenced database so created is a new, important PPR tool, that allows to extrapolate a number of significant data and generate thematic maps that will help to understand the types of areas and sites under preservation and the historically most considered Lombardy landscape components and above all will allow to read the consistent complexity of the protection system, both according to the article 136 of D.Lgs 42/2004, (the connection between the 556 landscape binding actions relating to the "overall beauty" and to the 332 landscape binding actions related to the so-called "individual beauties") and in accordance with the already mentioned different letters of the art. 142 of D.Lgs 42/2004, and both according to supra-national protections, such as Natura 2000 sites, Unesco sites, etc. in order to be able to more appropriately define not only the criteria for managing the bonded areas and sites, but also the possible revisions of the landscape preservation, with a PPR proposal of regional level safeguards.

The geo-referenced database thus drafted therefore contains a series of information useful for identifying critical points, values and potential of the preserved Lombardy heritage.

On the basis of this punctual analysis a further step was taken, namely to unite areas and sites of landscape value of considerable public interest, in aggregations and for each of them to define coordinated management and enhancement criteria, aimed at the planned preservation of bonded areas and sites, in order to adapt Lombardy PPR to the requirements of the Italian Preservation Code.

The geo-referenced database was a substantial reference for the definition of the already mentioned aggregations, in particular considering the preserved landscape connection records. The bonded areas and sites in this category are those that, due to characteristics emerging from the reading of the decree, belong to a unitary landscape system and

they are suitable for forming an aggregation. In that way it was possible to establish 60 aggregations of sites and areas of landscape value of considerable public interest for the "overall beauty" based on homogeneous or significantly connected landscape, territorial or geographical features and 5 typological aggregations of buildings and areas of landscape value of 
considerable public interest for the "individual beauties" based on assimilable typological characters.

\section{THE LANDSCAPE PRESERVATION GEOREDERENCED DATABASE AS A TOOL FOR PUBLIC USE}

The PPR review involved also the verification and reorganization of the overall PPR cartographic material by number, type and contents of each of the tables. It was also necessary to update the themes (in shapefile format) that set the cartography and to solve the problems about incompleteness, inaccuracy, imprecision of geo-referencing, etc.

At first it was necessary to collect and organize all the available material of geographic archives (defining projects in the ESRI ArcGis software environment) to elaborate thematic maps. The data used for the construction of the information apparatus of the new Lombardy PPR comes mainly from the Lombardy Region Goeportale (http://www.geoportale.regione.lombardia. it), access, consultation and acquisition portal of cartographic data. Other information layers were received directly from the various Regional and National Agencies. The updating of some of them has been possible due to the reports of the Offices of Lombardy Region - in charge of the preliminary exam and evaluation of the municipality planning tools subjected to the procedure of landscape authorization - that have discovered problems of incompleteness of the data or erroneous mapping of territorial components and features.

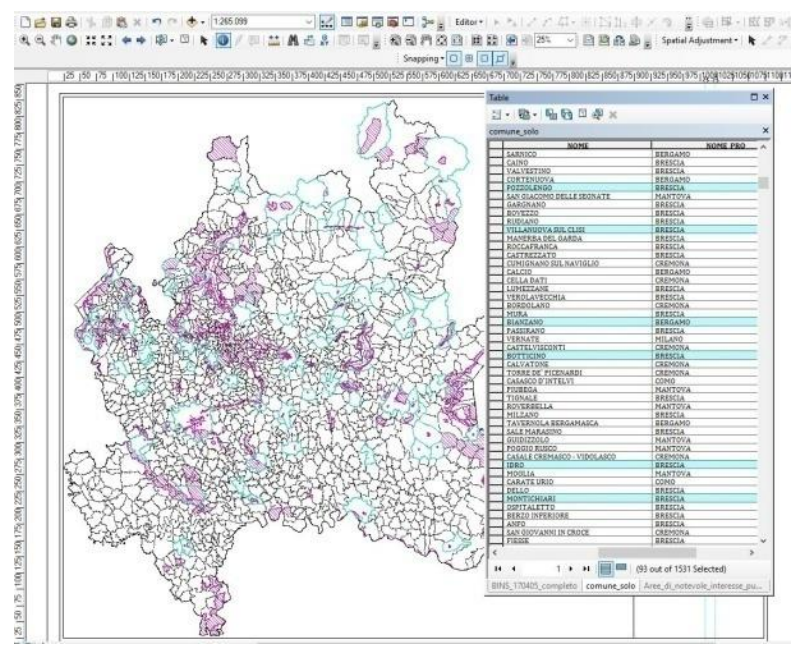

Figure 6. Lombardy PPR review: identification (in light blue) of the Lombardy municipalities with landscape preservation binding action at National level concerning the entirely municipal territory.

With particular regard to the census of the system of landscape preservation, a specifically dedicated Information System was set up with the aim of creating an overall univocal and exhaustive framework, as well as legally compliant, of the bonded areas and sites in Lombardy. The information contained in SIBA, the Lombardy Region Information and Landscape Information System, were implemented with information enclosed in the database of other Ministerial resources available online and were verified like already described.

The new PPR Plan Information System is an active tool to manage and update geographical information and the information layers that compose it are able to support regional and local users like offices responsible for verifying compliance with municipal urban planning, the Regional Landscape Commission, Local Landscape Commissions.

The goal is to create a common IT platform among the different subjects, capable to manage a cyclical process of sharing cartographic data that can be consulted and updated even at the local scale and to constitute a support tool for the local administrations responsible for managing the landscape, favoring a co-planning method by different institutions at different levels. This process generates a flow of data review, linking the local territorial information systems with the regional one. The proposal for structuring geographic plan information is part of the technological evolution in recent years of cartographic maps, production and distribution of geographical data in digital format by public bodies.

The recent national directives and policies, relative to the Open Data model in the Public Administration, promote the overcoming of the model that created separation between Public Agencies and citizens. Open Data not only responds to the need for transparency, but becomes a tool to promote public participation and inter-institutional collaboration.

In that way the cartographic material, that today constitutes the operational support to the PPR is a consulting geographic data that makes advanced use of Web technologies and the more general ones of the Open Source and Open Data, also in order to involve, inform and consult the citizen.

Regarding the landscape preserved system everyone - in Open Source - will be able to know preservation administrative data, for example which municipalities are partially or entirely under National Preservation law; landscape features mentioned in the preservation decrees and various NCAP (as previously explained); stratification and approach of Lombardy landscape preservation, knowing how many and which binding actions were issued before 1950, between 1950-1960, 1960-1970, after 1980, regarding specific landscape components. Comparing the bonded areas or sites description mentioned in the official declaration with the current situation, it is understandable if and how much the landscape changed in the last $30-50-60$ years.

By extrapolating the data organized in the database it is possible also to draw up - for each aggregation - the tables that summarize the main info of the database itself. In these tables there are clearly displayed 80 years of history of landscape preservation in Lombardy, for the first time organized in a unified manner: for this reason these tables are an integral part of the extensive preservation management criteria defined for the aggregations of bonded areas and sites (Figure 7).

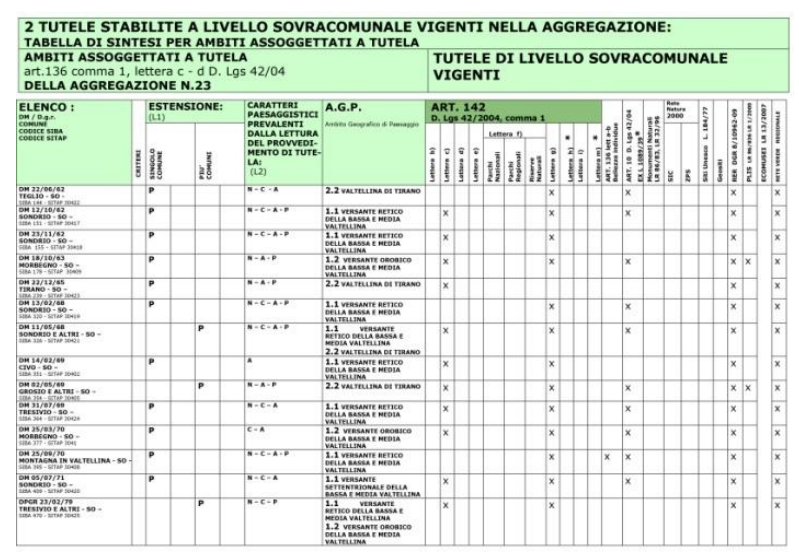

Figure 7. Lombardy PPR, review: Aggregation 23 of bonded areas and sites regarding Valtellina area: landscape preservation summary table derived from the georeferenced database. 
Thank to the geo-referenced database it is easier to comprehend that Lombardy landscape is extremely protected, for various reasons, at different levels, by different laws and regulations and also to understand the complexity and integration of the Lombardy landscape protections and more specifically to support the definition of preservation and planning coordinated management criteria.

\section{CONCLUSIONS}

The database allows to better understand the Lombardy landscape preservation system and to manage it in a proactive way, defining the composite Lombardy landscape as a complex to be conserved, but also valorized and rehabilitated.

The Lombardy PPR will be an innovative landscape open source WEBGIS based tool linking data, rules, planning components and planning apparatus that will provide better preservation management policies: it will allow users to download such data and to manage them within common open source GIS (as QGIS) or commercial licences, or to link them within WEB GIS or new application web accessible by desktop or by common devices (i.e. smarthphone).

\section{ACKNOWLEDGEMENTS}

The Lombardy Region (RL) initiated in 2013 the Piano Paesaggistico Regionale (Landscape Regional Plan - PPR) review, with the related Valutazione Ambientale Strategica (Strategic Environmental Assessment - VAS), to ensure that the new Lombardy PPR is in compliance with the Code of Cultural Heritage and Landscape, D.Lgs. 42/2004), that prescribes the definition of management criteria for every landscape area under binding action.

This review of the Regional Landscape Plan (PPR) now in progress has a scientific agreement with the Architectural and Urban Studies Department (DAStU) of the Politecnico of Milan (Piano Paesaggistico Regionale - PPR della Lombardia, Politecnico di Milano Dipartimento di Architettura e Studi Urbani - DAStU, Studi, ricerca e attività di supporto alla redazione del Piano Paesaggistico Regionale (Studies, research and support activities about Regional Landscape Plan definition), Department Director: Gabriele Pasqui, Scientific Leader: Andrea Arcidiacono, Responsible for Landscape Preservation Criteria: Alberta Cazzani, Research work group: Monica Aresi, Stefano Coloru Paolo Dilda, Viviana di Martino, Marika Fior, Federico Ghirardelli, Daniela Giannoccaro,Giulio Giordano, Carlo Manfredi, Silvia Restelli, Silvia Ronchi, Stefano Salata, Francesco Secchi)

This paper concernes the Lombardy PPR research of the Politecnico di Milano and specifically describes goals, analysis and results about the landscape areas and sites under National preservation in Lombardy.

\section{REFERENCES}

Arcidiacono, A., Cazzani, A., Pedrazzini. L., 2015. Obiettivi per il nuovo Piano Paesaggistico regionale lombardo. Valori ambientali, efficacia operativa e gestione delle tutele.In: Moccia, F.D., Sepe, M. (a cura di), Infrastrutture blu e verdi, reti virtuali, culturali e sociali, Special Issue di:"Urbanistica Informazioni" n.263, anno XXXXII, Settembre-Ottobre 2015, INU Edizioni, SezioneVI,Paesaggio, pp.7-10, ISSN:0392-5005.

Arcidiacono, A., Cazzani, A., 2016. A project to valorize the Lombardy landscape through the active management of National and Regional preservation tools. In: AA.VV, Tasting The Landscape, 53rd World Congress IFLA (International Federation of Landscape Architects)
Session Layered Landscapes, Torino, 20-22 April 2016, Edifir Edizioni Firenze, p.394, ISBN 9788879707817.

Biallo, G., 2013. a cura di, Dati Geografici Aperti: istruzioni per l'uso, I Quaderni di OpenGeoData Italia, Associazione OpenGeoData Italia; ISBN 978-88-908951-0-4, testo disponibile al sito: http://www.opengeodata.it (accessed 11.03.2019).

Bocher, E.; Neteler, M., 2012, ed./eds., Geospatial free and open source software in the 21st century, Dordrecht ... [etc.]: Springer: XIV, $261 \mathrm{p}$. ISBN: 978-3-642-10594-4 doi: 10.1007/978-3-642-10595-1.

Boriani,M., Cazzani, A., 2014, Cultural Heritage Preservation in Italy. In: Casnati, G. (edited by), The Politecnico di Milano in Armenia, Oemme edizioni, Venezia, pp. 33-42.

Brumana, R., Oreni, D., Cuca, B., Rampini, A., Pepe, M., 2013. Open access to historical information for landscape analysis in an SDI framework. International Journal of Agricultural and Environmental Information Systems (IJAEIS), 4(3), 18-40.

Cazzani, A., Coloru, S., 2016. Criteri per la gestione attiva dei vincoli e degli ambiti di tutela paesaggistica in Lombardia, Criteria for the Active Management of Landscape Protection limits and context in Lombardia. In: Territorio, nuova serie, n.77, II trimestre 2016, Franco Angeli, Milano, luglio 2016, pp. 31-37, ISSN 1825-8689.

Cultural Heritage and Landscape Italian Preservation Code, Il Nuovo Codice dei Beni Culturali e del Paesaggio, 2000,DL 42/2004(http://www.eui.eu/Projects/InternationalArtHeritageLaw/Italy. aspx).

De Robbio, A., 2013. Dati aperti nella Pubblica Amministrazione tra crescita e trasparenza, DigItalia, 1, 29-50.

Faini, F., 2015. «Italian Open Government Strategy in National and Regional Regulation», in Electronic Government and the Information Systems Perspective, pp. 271-286. Springer International Publishing.

Giannoccaro, D., Dilda.P., 2016. Costruzione e condivisione di dati geografici: il sistema informativo per la gestione del piano. Geographical Data Construction and Sharing: the Information System for the Management of the Plan. In: Territorio, nuova serie, n.77, II trimestre 2016, Franco Angeli, Milano, luglio 2016, pp. 63-66, ISSN $1825-8689$.

GEOPAN atl@s APP - http:// geoserver.atlas.polimi.it/ examples /servlets/Geopan/D/Entry/selector2b.html (Accessed 15.03.2019).

Mazzetti, P., Latre, M. Á., Ernst, J., Brumana, R., Brauman, S., \& Nativi, S., 2015. Virtual hubs for facilitating access to open data, in EGU General Assembly Conference (Vol. 17).

MIBAC (Ministero per i Beni e le Attività Culturali), SITAP -Sistema Informativo Territoriale Ambientale e Paesaggistico, 1996-2018. (http://www.sitap.beniculturali.it/)

Previtali, M. \& Latre, M.Á., 2018. A brokered Virtual Hub approach for the generation of web applications based on historical maps, Appl Geomat (2018) 10: 453. (https://doi.org/10.1007/s12518-018-0235-1, 453-472).

Regione Lombardia, Piano Paesaggistico Regionale (Lombardy Region, Landscape Regional Plan), 2010-2017. (http://www. regione.lombardia.it/wps/portal/istituzionale/HP/DettaglioServizio/servi zi-e-informazioni/Enti-e-Operatori/Territorio/ Pianificazione-regionale /piano-paesaggistico-regionale-ppr/piano-paesaggistico-regionale-ppr)

Regione Lombardia, SIBA - Sistema Informativo Beni e Ambiti Paesaggistici, 2018 (https://www.Cartografia .servizirl. it/ viewsiba/)

The European Landscape Convention, 2000, Florence, Italy (https://rm.coe.int/1680080621). 